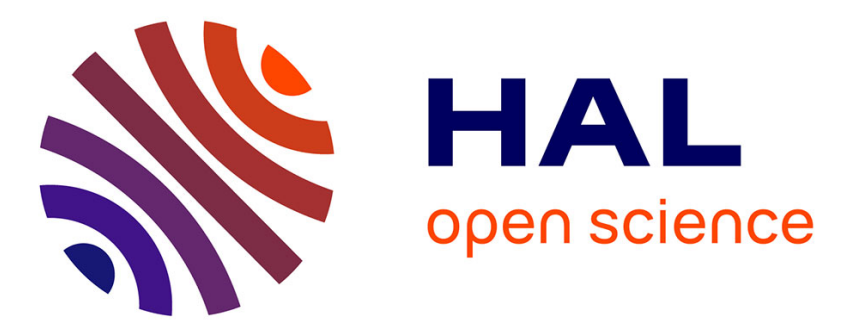

\title{
Age-related changes in co-speech gesture and narrative: Evidence from French children and adults
} Jean-Marc Colletta, Catherine Pellenq, Michèle Guidetti

\section{To cite this version:}

Jean-Marc Colletta, Catherine Pellenq, Michèle Guidetti. Age-related changes in co-speech gesture and narrative: Evidence from French children and adults. Speech Communication, 2010, 52 (6), pp.565-575. 10.1016/j.specom.2010.02.009 . hal-01292628

\section{HAL Id: hal-01292628 \\ https://hal.univ-grenoble-alpes.fr/hal-01292628}

Submitted on 25 May 2016

HAL is a multi-disciplinary open access archive for the deposit and dissemination of scientific research documents, whether they are published or not. The documents may come from teaching and research institutions in France or abroad, or from public or private research centers.
L'archive ouverte pluridisciplinaire HAL, est destinée au dépôt et à la diffusion de documents scientifiques de niveau recherche, publiés ou non, émanant des établissements d'enseignement et de recherche français ou étrangers, des laboratoires publics ou privés.

\section{(ㅇ)(1) $\$$}

Distributed under a Creative Commons Attribution - NonCommercial - NoDerivatives 44.0 


\title{
Age-related changes in co-speech gesture and narrative: Evidence from French children and adults
}

\author{
Jean-Marc Colletta ${ }^{\mathrm{a}, *}$, Catherine Pellenq ${ }^{\mathrm{b}}$, Michèle Guidetti ${ }^{\mathrm{c}}$ \\ "Université Stendhal, Laboratoire Lidilem (EA 609), 1180 Avemue Centrale, BP 25, 38040 Grenoble Cedex 9. France \\ ${ }^{\mathrm{b}}$ IUFM \& Université Joseph Fourier, Laboratoire des Sciences de l'Education (EA 602), 30 Avenue Marcelin Berthelot, 38100 Grenoble, France

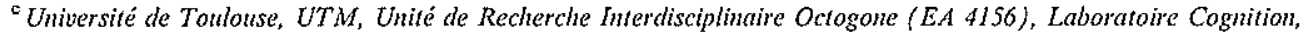 \\ Communication et Développement (ECCD), Pavillon de la Recherche, 5 Allées A. Machado, 31058 Toulouse Cedex 9, France
}

\begin{abstract}
As children's language abilities develop, so may their use of co-speech gesture. We tested this hypothesis by studying oral narratives produced by French children and adults. One hundred and twenty-two participants, divided into three age groups ( 6 years old, 10 years old and adults), were asked to watch a Tom and Jerry cartoon and then tell the story to the experimenter. All narratives were videotaped, and subsequently transcribed and annotated for language and gesture using the ELAN soltware. The results showed a strong effect of age on language complexity, discourse construction and gesture. The age effect was only partly related to the length of the narratives, as adults produced shorter narratives than 10-year-olds. The study thus confrrms that co-speech gestures develop with age in the context of narrative activity and plays a crucial role in discourse cohesion and the framing of verbal utterances. This developmental shift towards more complex narratives through both words and gestures is discussed in terms of its theoretical implications in the study of gesture and discourse development.
\end{abstract}

Keywords: Co-speech gestures; Narratives; Multimodality; French children and adults

\section{Introduction}

The multimodal nature of face-to-face spoken comnunication has been well established by gesture researchers over the past few decades (Kendon, 1980, 2004; McNeill, 1992; Calbris, 2003). Today, there is common agreement that spoken communication emerges through multimodal channels, linking together words, voice and gestures. Moreover, there is growing evidence that the speaker or listener integrates auditory (linguistic, prosodic) and visual (gesture) information into a single message (Rimé and

\footnotetext{
- Corresponding author. Tel.: +33 (0) 476826843 .

E-mail addresses: jean-marc.colletta@u-grenoble3.fr (J.-M. Colletta), catherine.pellenq@ujf-grenoble.fr (C. Pellenq), guidetti@univ-tlse2.fr (M. Guidetti).
}

Schiratura, 1991; Feyereisen, 1994; Thompson and Massaro, 1994; Hadar and Butterworth, 1997; Beattie and Shovelton, 1999; Mayberry and Jaques, 2000; Kita and Özyürek, 2003; Kita et al., 2007; Ozyurek et al., 2008). Psycholinguistic research has drawn on these observations to generate models intended to formalise the relationship between speech and gesture (McNeill and Duncan, 2000; de Ruiter, 2000; Kita, 2000; Kita and Özyürek, 2007). As Gullberg et al. (2008a, p. 151) point out, these models "[...] differ in their views of the locus and the nature of the link", with some models regarding gestures as an integral part of the utterance and others considering them to be semiotic auxiliaries to speech or to the speech production/ comprehension process.

Identifying the way in which speech and gesture are linked throughout the language acquisition process would bring new insights into this theoretical issue. However, 
the multimodal study of child language still has a long way to go. Although there is a considerable body of work on the communicative behaviour of very young children (see Van der Stratten, 1991; Marcos, 1998; Guidetti, 2003, or Ducey-Kaufmann, 2007, for more details), considerable controversy still surrounds the classification of gestures before the age of two. The well-known distinction between deictic and representational gestures (see, for example, Capirci et al., 1996) has recently been reconsidered, and a separate category was created for conventional gestures, which were previously included in the representational category (see, for example, Guidetti, 2002).

The first representational gestures include predicates like raising the arms high for "tall" or waving the hands for "too hot", and nominal gestures which act as labels for objects or elements in the environment. The latter are obviously children's inventions which disappear as the language is mastered (e.g., gestures to imitate actions like pretending to drink out of a glass, or gestures to imitate movements like closing and opening one's mouth to mean "fish", etc.). The representational category also includes conventional gestures like head-shaking and nodding to mean refusal and agreement, and waving goodbye. However, unlike representational gestures, conventional gestures do not disappear from the child's repertoire, even once speech has become the privileged means of communication (Iverson and Goldin-Meadow, 1998, p. 2). Also called "emblems", they are subject to a consensus or convention, and are produced and understood by all the members of a given cultural group. They appear before language, in the form of pointing, nodding and head-shaking (see Guidetti, 2002), and interplay with the child's first spoken words during the one- to two-word transition period (Butcher and Goldin-Meadow, 2000; Capirci et al., 2002; Goldin-Meadow and Butcher, 2003; Capirci and Volterra, 2008). Including pointing in the conventional gestures category in no way plays down the specificity of deictic pointing gestures and "the link and differences between deixis and symbols in children's early gestural-vocal system", as nicely shown by Pizzuto and Capobianco (2007).

Considering the period beyond the preverbal stage, we still know little about the way in which gesture and multimodal speech develop after the age of 2 years. Functional uses of gesture change, and other types of gestures, such as abstract representational gestures and beats, have been identified as part of the gestural repertoire in studies of older children's bodily behaviour whilst performing oral explanations and narratives (McNeill, 1992; Colletta, 2004; Colletta and Pellenq, 2009; Graziano, 2009). Nevertheless, the precise manner in which all these gestures interact with more specific linguistic features of speech remains largely unknown and has so far been sparsely documented.

With regard to the gestures that accompany oral narratives, until recently, most available observations have concerned narratives produced by adults (McNeill, 1992; Streeck and Knapp, 1992; Léonard and Pinheiro, 1993;
Bouvet, 2001; Kita and Özyürek, 2003). Some authors have investigated aspects of children's multimodal language behaviour that are thought to accompany the narration of events, namely the way in which children speaking different languages and from different cultures use speech, gesture or both modalities to express manner and trajectory in the depiction of motion (Gullberg et al., 2008b; Ozyurek et al., 2008). However, these authors focused on selected aspects of depiction as a language activity indirectly related to narrative behaviour, rather than describing specific narrative abilities. Nor did they study gesture in its entirety, looking only at the representational gestures that are relevant to the expression of motion. McNeill (1992), too, analysed children's narratives from a multimodal perspective, but only took representational gestures into account in his observations.

In recent studies of spontaneous narratives produced by children aged 6-11 years during interviews with an adult (Kunene and Colletta, 2007; Colletta, 2009), it has been found that older children ( 9 years and over) use co-speech gesture in a similar way to adults and for several purposes: the representation of the narrated events and characters' attitudes, abstract deixis to mark discourse cohesion, pragmatic framing of the utterance, discourse connotation, discourse demarcation between the processing of the event frame and the speaker's comments, and synchronisation between speaker and listener. Other observations (Capirci et al., 2007; Graziano, 2009) also suggest that gestures become increasingly intertwined with speech, as children grow older.

In order to investigate the nature and strength of the developmental changes reported in the study of spontaneous narratives, 122 French children and adults were asked to tell a story illustrated in a short cartoon extract in controlled conditions. Our aim was to elicit the same kind of language behaviour in all three age groups (6-year-old children, 10-year-old children and adults), and to test the following hypotheses on the basis of a large body of data:

1. Narrating a story is a relatively complex language production task and previous studies have demonstrated age-related changes in both oral and written narration (Fayol, 1985; Bamberg, 1987; Berman and Slobin, 1994; Hickmann, 2003). We expected the adults to produce longer and more detalled narratives than the 10 year-olds, and the 10-year-olds to produce longer and more detailed narratives than the 6-year-olds.

2. As narratives gain in length and verbal information, they can be assumed to contain more cohesion cues, such as connective markers linking clauses and anaphoric expressions maintaining reference throughout the telling of the story. We therefore expected connectors and anaphors to be present in greater number in the adults' narratives than in the 10-year-olds' ones, and in greater number in the 10-year-olds' narratives than in the 6-year-olds' ones. 
3. Previous research on oral narratives (Labov, 1978; Laforest, 1996) has highlighted their pragmatic heterogeneity. Telling a story involves not only narrating the events, but also commenting on them or on the narration itself. A preliminary study of spontaneous narratives (Colletta, 2004) suggested a strong effect of age on non-narrative discourse acts: children did not seem able to insert comments into their narratives until they reached the age of 9 or 10 years. We hypothesized that there would be a shift towards a more complex discourse structure, reflected in a greater number of non-narrative acts in the adults' narratives than in the 10-year-olds' ones, and a greater number in the 10-year-olds' narratives than in the 6 -year-olds' ones.

4. Considering the close relationship between gesture and speech evidenced in many studies, we hypothesized that, as narratives gained in length and verbal information, they would contain more co-speech gestures. Consequently, the adults would gesture more than the 10year-olds who, in turn, would gesture more than the 6year-olds.

5. As narration is a specific language behaviour, we expected that some types of gestures would be over-represented, compared with other types. Representational gestures that help to represent events and characters, discourse cohesion gestures that help to mark clause relations, and framing gestures that help to express the speaker's intentions should be extensively used in the context of a narrative activity. As we postulated that there would be age-related changes in discourse cohesion, as well as in discourse construction, we expected to find more cohesive and framing gestures in the adults' narratives than in the 10-year-olds' ones, and more in the 10-year olds' narratives than in the 6-year-olds' ones.

6. According to developmental studies of gesture-speech combinations during the one- to two-word transition period (Capirci et al., 2002; Goldin-Meadow and Butcher, 2003), after the onset of redundant combinations, young children start to use complementary and supplementary combinations, thus becoming able to express two ideas at the same time, and later to produce their first two-word utterances. The present study sought to ascertain whether this developmental schema also applies to subsequent stages of language acquisition.

\section{Method}

\subsection{Participants}

The participants were 84 French-speaking children aged $6(M=5.8 /$ range $=5.3-6.5)$ and 10 years $(M=10 /$ range $=8.9-11$, with 41 participants in the younger group and 43 in the older one, along with 38 adult native French speakers $(M=21 /$ range $=18-33)$. There were nearly equal numbers of males and females in all age groups: the 6-yearold group contained 16 girls and 25 boys, the 10-year-old group 21 girls and 22 boys, and the adult group 21 women and $17 \mathrm{men}$. The children attended preschools and primary schools in predominantly upper-middle-class districts of Grenoble and Toulouse, while the adults were college students living in Grenoble and Toulouse.

\subsection{Procedure}

The participants were asked to watch a wordless Tom and Jerry cartoon extract ( $2 \mathrm{~h} 47 \mathrm{~min}$ ) and tell the story it depicted. The cartoon starts with a mother bird leaving her egg in the nest. The egg accidentally falls out and rolls into Jerry's house. The egg hatches in Jerry's house and a baby woodpecker emerges. The baby bird then starts damaging Jerry's furniture. After a few failed attempts to calm the bird down, Jerry gets angry and decides to put the bird back in its nest. The participants' narratives were videotaped for later analysis. The mean length of each narrative was $2 \mathrm{~h} 30 \mathrm{~min}$, and the total amount of recorded video was approximately $5 \mathrm{~h}$.

\subsection{Data analysis}

\subsubsection{Coding}

The data transcription and annotation was performed using the ELAN software (http://www.mpinl/tools/), as well as an annotation scheme specially designed for this study (Colletta et al., 2009), , providing information on syntax, lexicon, discourse and co-speech gesture. A copy of the annotation window file is provided in the appendix.

\subsubsection{Speech coding}

The coding of speech is a complex issue. For a start, the sentence is not an adequate descriptive unit for spoken language, as it is for written language. Second, although linguists tend to use the term "utterance" when describing spoken language, there is no proper definition of an utterance that could lead us to easily identify such units in everyday discourse. Speech coding was therefore performed with particular reference to Berman and Slobin (1994) and to Jisa (2000), taking the number of clauses as a measure of the length of linguistic productions. A clause was defined as a predicate matched by one, two or three arguments (logical approach), corresponding to a series of words including a verb and its satellites, such as the subject and any complement(s) (grammatical approach). We then measured the total number of words (tokens) and, within that total, the number of subordination markers (relative pronouns, conjunctions or prepositions beginning non-finite and participial clauses). The clause and word counts allowed us to estimate the length of the narrative performed by each subject.

\footnotetext{
' In consultation with M. Augustyn, G. Calbris, O. Capirci, C. Cristilli, O. Ece Demir, S. Goldin-Meadow, M. Grandaty, M. Graziano, B. Guidarelli, A. Kendon, R. Kunene, S. Levine, L. Miladi, A. Millet, S. Mugnier, S. Özçaliskan, J.-P. Simon and A. Venouil.
} 
As with subordination markers, the literature on the later stages of language development describes the acquisition of syntax as a gradual process of complexification, with the child mastering simple or independent sentences way before complex sentences, including relative, completive, non-finite and other subordinate clauses (see Diessel, 2004 , for a review). In our view, although measuring subordination markers provides information about the level of language complexity attained by a subject in a given language task, it does not necessarily reflect discourse abilities (Jisa, 2004; Tolchinsky, 2004).

To gauge these discourse abilities, we therefore chose to measure the number of connectors and anaphors, and to study the narratives' structure. Connective markers and anaphoric expressions serve discourse cohesion purposes at the micro-level of discourse (Halliday and Hasan, 1976; Lundquist, 1980). Connectors selected here included all the words that play a role in marking either the discourse structure or the logical, chronological, spatial, argumentative and other relations between clauses, such as "well", "now", "okay", "so" or "then", "later", "therefore", "because", "consequently", etc. Anaphors selected here included all the words that help to maintain the identity of referents throughout the text, such as pronouns and relative pronouns (e.g. "...the egg, which has been left alone by the Mummy Bird, moves around the nest, then $\underline{i t}$ falls down onto a cobweb and a flower, and $\underline{i t}$ rolls into Jerry's house. .."), definite determiners (e.g. "...first we see a broody mummy bird, and the mummy bird is knitting..."), lexical repetitions (e.g. "...Jerry wants to stop the baby damaging the furniture, but the baby pecks his arm...") and nominal substitutes (e.g. "... Jevy wakes up and jumps out of bed. The mouse does not understand why an egg is lying there...").

Assessing discourse abilities at the pragmatic level involves the study of discourse structure. Whether the story to be told originates from the speaker's own experience, from literacy or from the shared cultural knowledge of ethnic and social groups, telling a story can be viewed as a complex language behaviour that usually combines narration and commentary (Labov, 1978; Laforest, 1996). Therefore, a narrative may be analysed as a main discourse act (the act of narrating events) preceded by, incorporating or followed by explanations, evaluations, metadiscourse and other types of commentary acts. In order to account for the discourse structure of the collected narratives, we labelled each clause in each narrative according to the discourse act it expressed, either on its own or with other clauses. We defined four types of discourse acts (Colletta et al., 2009):

- "Narration", where the clause provided a description of an event seen in the cartoon excerpt or stated the explicit dimension of this event: the subject recounted the event such as it appeared in the cartoon.

- "Explanation", where the clause provided information of a causal nature: the subject included an additional explanation of the narrated event, such as it appeared in the cartoon (e.g. "then afterwards Jerry tries to sit down because he is tired").

- "Interpretation", where the clause presented an inference or a free interpretation concerning the event or a character's intentions: the subject invented something based on the event, formed a hypothesis, drew unseen conclusions (e.g. "then the mummy looks at her alarm clock she realizes that it is time to leave").

- "Comment", where the clause dealt with neither the explicit nor the implicit aspects of the course of events, but instead presented either a "meta-narrative comment" (McNeill, 1992) relating to a character, action or aspect of the story, or a "para-narrative comment" (McNeill, 1992) relating to the action of telling the story (judgement, personal appreciation, etc.) (e.g. "it is a crazy bird, I like it when the egg falls into the spider's web").

\subsubsection{Gesture coding}

2.3.3.1. Gesture units. The first step was to pinpoint the gesture units performed by each subject during the narrative production. Our method was based on Adam Kendon's proposals. ${ }^{2}$ In order to decide whether or not a movement should be counted as a gesture unit, the coder took the following three criteria into account: movement, location and configuration, assessing each one on a 2-point scale as follows:

- Movement: if the movement could be easily perceived and was of sufficient amplitude and speed, it was attributed 2 pts, if it could not be easily perceived and was of insufficient amplitude and speed, it was attributed $0 \mathrm{pt}$, if it was between the two, it was attributed $1 \mathrm{pt}$.

- Location: if the gesture was performed in front of the speaker, in full view of the listener, it was attributed 2 pts, if it was performed to one side and was almost, if not impossible, for the interlocutor to see, it was attributed $0 \mathrm{pt}$, if it was between the two, it was attributed $1 \mathrm{pt}$.

- Configuration: if the configuration (in the case of a manual gesture) corresponded to a precise hand shape or a well-marked trajectory, it was attributed 2 pts, if it had an imprecise form or trajectory, it was attributed $0 \mathrm{pt}$, if it was between the two, it was attributed $1 \mathrm{pt}$.

For a gesture to be counted as a unit it had to score 3 or more points.

2.3.3.2. Gesture form and function. The gestures were then described and classified according to their form and function. Seven different types of gestures were selected ${ }^{3}$ :

\footnotetext{
2 Proposals presented in Grenoble in July 2007, during a symposium on gesture and language development. Also see Kendon (2004, pp. 10-15).

${ }^{3}$ More details about the coding scheme can be found in Colletta et al. (2009)
} 
- "Deictic", where the hand or head gesture pointed to an object present in the communication setting, to the interlocutor, or to the speaker or part of his or her body to refer to this object or person, or else indicated the direction in which the referent was to be found, based on the actual coordinates of the physical setting, e.g. the speaker pointed to himself while saying "this is what I understood".

- "Representational", where the hand or facial gesture, possibly in conjunction with other parts of the body, represented an object or a property of that object, a place, a trajectory, an action, a character or an attitude, or else symbolised an abstract idea through metaphor or metonymy, e.g. the two hands forming an oval to represent an egg (depiction of an object); a downward movement of the hand or index finger to represent the fall of the egg (depiction of a trajectory); a pointing gesture towards a spot in the frontal space to locate an absent referent; an open hand gesture with palm up to represent the story to be told (the "conduit metaphor", as described in McNeill, 1992, pp. 147-151).

- "Performative", where the gesture either enacted a nonassertive speech act (response, question, request for confirmation, etc.), or reinforced or modified the illocutionary value of a non-assertive speech act, e.g. nodding one's head in agreement, a shrug of the shoulders, possibly associated with a dubious expression, to convey ignorance in answer to a question.

- "Framing", where the gesture occurred during the narration (during the telling of an event, or during a comment on either a particular aspect of the story or the narration itself) and expressed the speaker's emotional or mental state, e.g. the subject's face showing amusement to express the comical side of a situation.

- "Discursive", where a generally brief gesture helped to structure speech and discourse by accentuating or highlighting certain linguistic units, or marked discourse cohesion by linking clauses or discourse units with the help of gestures performing an anaphoric function or gestures accompanying connectors, e.g. rhythmic movements (beats) of the head or hands accompanying the accentuation of certain words or syllables, beats accompanying comnectors, pointing towards a spot which previously represented the verbalised referent.

- "Interactive", where a gesture was accompanied by a glance towards the interlocutor to indicate that the speaker required or wished to verify the latter's attention, or had reached the end of the speech turn or narrative. For example, nodding the head while the interlocutor spoke or turning the head and gazing towards the interlocutor at the end of a speech turn.

- "Word searching", where a hand gesture or a facial expression indicated that the speaker was searching for a word or expression. For example, frowning and staring upwards whilst searching for words or tapping fingers with a reflective expression.
2.3.3.3. Gesture-speech combinations. Six types of gesturespeech combinations were identified ${ }^{4}$ :

- "Reinforcement", where the information supplied by the gesture was identical to the linguistic information it was related to, e.g. head nodding accompanied by an aflirmative "yes" or a shrug accompanied by "I don't know" as a doubt-filled response. This term did not apply to "representational" gestures, for like McNeill (1992), Calbris (2003) and Kendon (2004), we deemed that the information provided by a representational gesture was always greater than the linguistic information.

- "Supplementation", where the information supplied by the gesture not only served to specify the related linguistic information, but also added a supplementary meaning. This was the case for representational gestures providing a supplementary meaning such as 'push' + pointing to couch. This was also the case for framing gestures providing a supplementary meaning, such as when the child's face showed signs of amusement to express the comical side of the event being narrated. All the "framing" gestures were described as "supplements", unless they contradicted the verbal message (cf. fourth category).

- "Integration", where the gesture did not add any supplementary information to the verbal message but did make it more specific, e.g. "she leaves" while making a leftward movement of the left hand to indicate the direction of her movement, or "it makes the mouse move" accompanied by an oscillation of the hand representing Jerry shaking. This category only contained "representational" gestures.

- "Contradiction", where the information provided by the gesture was not only different from the linguistic information to which it was linked, but actually contradicted it. This category only contained "framing" and "performative" gestures.

- "Complement", where the information provided by the gesture was a necessary addition to the incomplete linguistic information provided by the verbal message: the gesture disambiguated the message, e.g. a pointing gesture accompanying a location adverb, such as "here", "there". This category only contained "deictic" gestures. - "Substitution", where the information provided by the gesture replaced the linguistic information, e.g. nodding in an affirmative response or a shrug matched with a facial expression showing ignorance as a response expressing doubt without any verbal utterance.

2.3.3.4. Gesture rate. Previous studies (Nicoladis et al., 2008) have reported that people who speak for longer are likely to produce a higher proportion of gestures. To

\footnotetext{
${ }^{4}$ Our classification was based on previous researci by Özçaliskan and Goldin-Mendow (2006), and by Capirci and Volterra (2008), as there is no widely accepted, standardized coding system. Rescarchers also lack precise and appropriate notations for gestural productions.
} 
account for individual and age group differences, we calculated the gesture rate by counting the number of gestures and dividing it by the number of clauses used to tell the story.

\subsubsection{Reliability}

In order to establish reliability in gesture coding, two separate coders identified the gesture units for all our data, attributing a function to each stroke and classifying its relation to speech. A third coder validated their annotations and settled any disagreements. Interrater agreement was $90 \%$ on gesture identification (Colletta et al., 2009).

\section{Results}

The preliminary analysis failed to reveal any significant gender differences in any of our dependent measures. All subsequent statistical analyses were therefore performed across both genders. Most of the analyses we performed were ANOVAs, with age (6- and 10-year-olds and adults) as the between-subjects factor. In some cases, described below, some types of measures were used as within-subjects factors. First, we analysed the linguistic aspects of the narratives. Second, we analysed their gestural aspects as well as the gesture-speech combinations.

\subsection{Results from the linguistic analysis}

First, we analysed the number of clauses and the number of words that the participants in each age group used to tell the story, as a measure of the narratives' length. For both measures, we found the lowest means for the 6 year-olds' narratives, and the highest means for the 10 year-olds' narratives, with intermediate means for the adults' narratives (see Table 1). We observed a significant effect of age on the numbers of clauses $(F(2,119)=12.15$, $p<.0001)$ and words $(F(2,119)=10.09, p<.0001)$, and both post hoc tests (Bonferroni, $p<.05$ ) showed that the 6 -year-olds were significantly different from the 10-yearolds and the adults, but that the 10-year-olds did not differ significantly from the adults. Although we expected a constant and linear shift towards longer narrative productions in adults, our results paint a very different picture of narrative development in such a constrained task. This unexpected result may find an explanation in previous research on the development of summarizing abilities. As psycholinguistic research has shown (Fayol, 1985; Gombert, 1990), children do not really understand the point of summarizing stories until they reach the last 2 years of

Table 1

Mean numbers (S.D.) of words, clauses and gesture strokes (S.D./range) for each age group.

\begin{tabular}{lllc}
\hline & Words & Clauses & Gesture strokes \\
\hline 6.Ycar-olds & $166.71(84.96)$ & $26.02(14.23)$ & $7.07(7.42 / 0-31)$ \\
10-Year-olds & $262.02(122.63)$ & $44.33(21.82)$ & $22.02(27.74 / 0-155)$ \\
Aduits & $231.13(80.77)$ & $37.18(13.49)$ & $28.61(21.12 / 2-79)$ \\
\hline
\end{tabular}

primary school (9-11 years of age) and have great difficulty summarizing texts at secondary school. We hypothesise that children aged below 10 years who are given the task of narrating from a cartoon (or any other story document) try to tell the story in its entirety, one event after another, whereas children over 10 try to give summarized accounts of the story, in a more adult-like way. Our observations from another set of data (as yet unpublished) show that 11-year-old children give shorter and more summarized accounts than 10 -year-olds.

These initial results on the present corpus prompted us to take narrative length into account in our subsequent analyses. We took the number of clauses as our basis, rather than the number of words, as the latter has been found to be less relevant for studying the discursive and gestural dimensions of linguistic productions, as underlined by several authors (McNeill, 1992; Fayol, 1997; Kita and Özyürek, 2003).

Second, we analysed the syntactic complexity of the collected narratives. As seen in Fig. 1, the rate of subordination markers (number of subordination markers per clause) increased regularly with age. We found a significant effect of age on the number of subordination markers per clause $(F(2,119)=51.22, p<.0001)$, and the post hoc test (Bonferroni, $p<.05$ ) showed that the 6-year-olds used subordination markers significantly less than the 10-year-olds who, in turn, used them significantly less than the aduits. This result confirmed the expected trend towards more complex syntax with age, even though the adults produced shorter narratives than the 10 -year-old children.

Third, we analysed the discourse cohesion markers in the collected data. As seen in Fig. 2, we found a significant effect of age on the rate of connectors (number of connectors per clause: $F(2,119)=10.18, p<.0001)$ and on the rate of anaphors (number of anaphors per clause: $F(2,119)=13.13, \quad p<.0001)$. However, these results reflected two very different patterns of development. The post hoc test (Bonferroni, $p<.05$ ) showed that there were significantly fewer connectors in the adults' narratives than

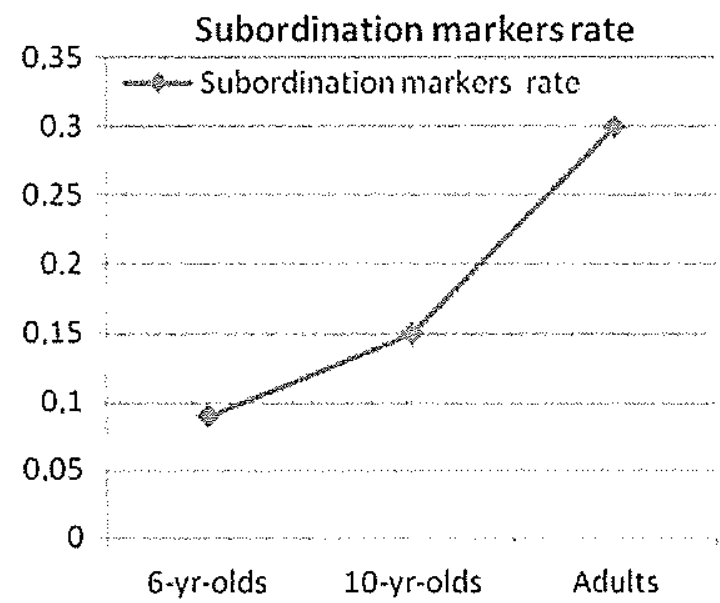

Fig. 1. Subordination markers rate (number of occurrences per clause) for each age group. 


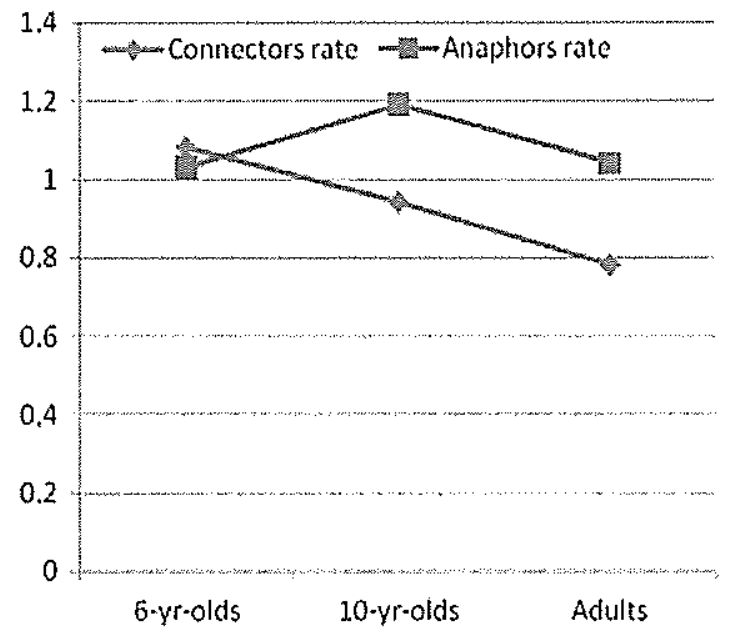

Fig. 2. Cohesion markers rate (number of occurrences per clause) for each age group.

in the 6-year-olds' narratives, with intermediate means in the 10-year-olds'narratives. To account for this unexpected fall, we can hypothesise that connective links tend to become more implicit with age. Research in textual psycholinguistics (see Sperber and Wilson, 1989; Coirier et al., 1996; Fayol, 1997) has shown that, even in the absence of connective markers, sequences of clauses can still be interpreted, due to the inferential nature of communication.

As for anaphoric markers, the post hoc test (Bonferroni, $p<.05$ ) showed that the 10 -year-olds used significantly more anaphors than both the 6-year-olds and the adults. This result confirmed the expected change between 6 and 10 years, with more anaphors in the older children's narratives, but not between 10 years and adulthood. The fact that the adults' narratives, though shorter than those of the 6-year-olds, did not contain a greater number of anaphoric markers, can, however, be explained by the fact that they contained sequences of clauses with subject ellipsis, and therefore, ummarked anaphors (phenomenon also observed by Jisa (2000)). The marking of interclause relations also tends to become more implicit in adults. It would be interesting to find out whether there is a tendency in this area for gestures to take over from linguistic markers, in other words, whether the proportion of discursive gestures increases with age.

Fourth, we analysed the discourse structure of the narratives. As described in Section 2, we counted the number of narrative, explanatory, interpretative and commentary clauses produced by the participants, who were free to perform any of the corresponding discourse acts - narration, explanation, interpretation and commentary - whilst telling the story (see Table 2 for results). We performed an analysis of variance, with age as a between-subjects factor and pragmatic type of clause as a within-subjects factor. We observed an effect of age $(F(2,119)=12.50, p<.0001)$, an effect of type of clause $(F(3,357)=404.05, p<.0001)$ and a significant interaction between the two variables $(F(6,357)=15.6, p<.0001)$. Post hoc Bonferroni tests showed that the age effect for the most frequent pragmatic type of clause (narrative clauses) only concerned the difference between the 10-year-olds and the other two groups $(p<.05)$.

By far the most interesting results were generated by grouping together all the non-narrative clauses. As seen in Fig. 3, the number of non-narrative clauses increased with age, and their proportion was far higher in the adults' productions than in the children's. We found a significant effect of age on the number of non-narrative clauses $(F(2,199)=35.04, p<.0001)$ and the post hoc test $(p<.05)$ showed that the 6-year-olds' use of non-narrative clauses was significantly lower than that of the 10-year-olds which, in turn, was significantly lower than that of the adults.

To sum up the linguistic analysis, although the adults produced shorter narratives than the 10-year-olds and used fewer cohesion devices, they used significantly more complex sentences to tell the story and commented, explained and interpreted the narrated events to a significantly greater extent than the 10-year-olds. This shift towards both more complex syntax and more complex discourse structures was also seen in the 10-year-olds, in relation to the 6-year-olds. While it is difficult to establish a link between complex syntax and gesture, it is easy to see why increasingly complex discursive behaviour at the pragmatic level might give rise to more markers in the kinesic modality. This hypothesis is supported by our own observations (Colletta, 2004, 2009), as well as those of Graziano (2009). Furthermore, given that co-speech gestures can serve textual functions (discourse cohesion markers), it would be interesting to find out whether a reduction in the explicit use of verbal cohesion indicators, as was the case for the adults compared with the 10-year-old children, is partly compensated for by recourse to gestures capable of fulfilling this function.

\subsection{Results from the gesture analysis}

Firstly, as seen in Table 1 , the data revealed an effect of age on the total number of gestures $(F(2,119)=11.35$,

Table 2

Mean numbers (S.D.) of pragmatic types of clauses for each age group.

\begin{tabular}{llll}
\hline & Narrative clauses & Explanatory clauses & Interpretative clauses \\
\hline 6-Year-olds & $22.59(13.42)$ & $0.66(1.15)$ & $1.39(1.69)$ \\
10-Year-olds & $37.70(18.02)$ & $1.19(1.83)$ & $3.58(3.68)$ \\
Adults & $24.42(9.61)$ & $1.58(1.87)$ & $5.95(3.99)$ \\
\hline
\end{tabular}




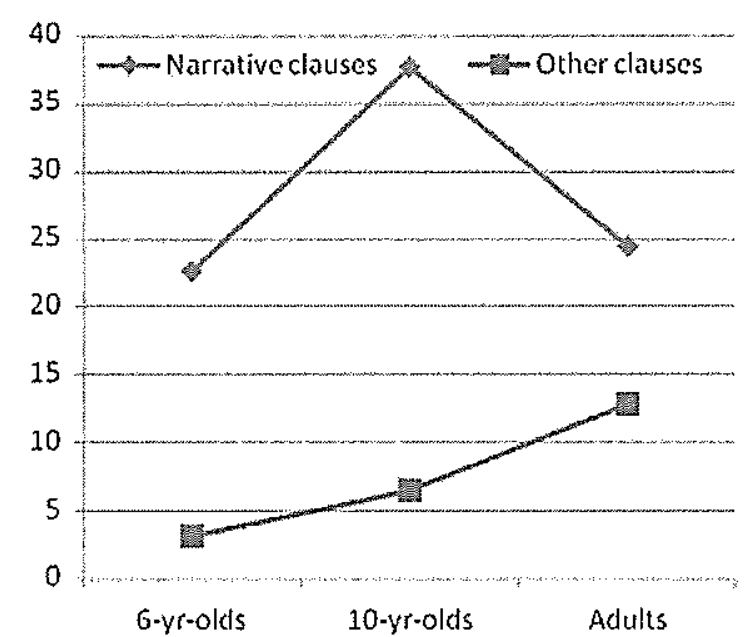

Fig. 3. Narrative clauses os other than narrative clauses for each age group.

$p<.0001$ ). Post hoc Bonferroni tests showed that the age effect only concerned the difference between the younger children and the other two groups $(p<.05)$. In other words, the 10-year-olds and adults gestured far more than the 6-year-olds. We then sought to ascertain whether an analysis based on gesture rate rather than on gesture number would yield the same result. As we mentioned in Section 2.3.3.4, there is evidence to suggest that people who speak for longer are likely to produce a higher proportion of gestures. This co-variation between speech and gesture might thus explain why the 10 -year-olds gestured more than the 6-year-olds.

As seen in Fig. 4, gesture rate increased regularly with age. The ANOVA revealed an effect of age on the gesture rate per clause $(F(2,119)=18.62, p<.0001)$. Post hoc Bonferroni tests $(p<.05)$ showed that when we controlled for discourse length, the adults gestured significantly more than the 10-year-olds, who gestured significantly more than the 6-years-olds while narrating their story. The increase in gesture use with age is the main finding of our study. While

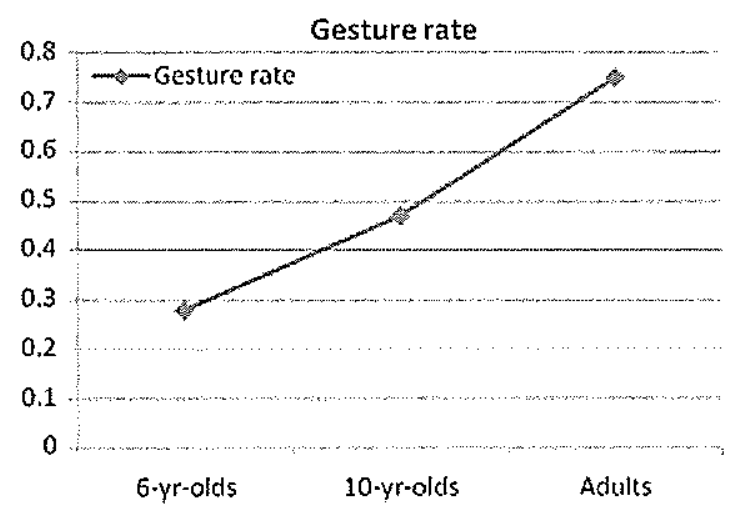

Fig. 4. Gesture rate (number of occurrences per clause) for each age group. this was the development we had expected, the fact that it remained significant when we had controlled for the length of the verbal production confirmed that there is indeed a development in the use of co-speech gestures with age, and that this development accompanies the changes in narrative behaviour.

Secondly, we analysed the types of gesture produced according to age. As we hypothesized in Section 1, the analysis revealed sparse use of the following types: deictic, performative, interactive and word searching. This stemmed from the specific nature of the language task. A speaker telling a story from a cartoon rarely needs to point to concrete referents present in the physical setting, nor does he or she have to perform the speech acts (question, request, acceptance, refusal, etc.) and interactive signals (e.g. the head nod as a backchannel signal) that are usually required in dialogue. As for word-searching gestures, in addition to their low occurrence, they were not particularly relevant here. Consequently, data relating to these four types of gesture were excluded from the analysis. By contrast, representational, framing and discursive gestures are assumed to play a role in the process of telling a story: the first by virtue of their imaging properties, the second by virtue of their expressive and connotative properties, and the third by virtue of their role in marking cohesion. Consequently, our statistical analysis was based on these three remaining types of gesture. In order to control for the effect of narrative length, we not only considered their number (see Table 3), but also their rate (i.e. the number of gesture strokes per clause, see Fig. 5). Type of gesture was regarded as a within-subjects factor.

The ANOVA showed that there was an effect of age $(F(2,119)=26.60, \quad p<.0001)$ and of type of gesture $(F(2,238)=40.97, p<.0001)$, but the interaction between age and type of gesture $(F(4,238)=2.31, p=.059)$ did not reach significance. Post hoc Bonferroni tests $(p<.05)$ showed that the age effect for the most frequent type of gesture (representational gestures) only concerned the difference between the younger children and the other two groups. The most interesting result was the rate of non-representational gestures (i.e. framing and discursive gestures), which increased more with age than the rate of representational gestures (see Fig. 5). We found a significant effect of age on the rates of both framing gestures $F(2,119)=14.29$, $p<.0001)$ and discursive gestures: $F(2,119)=29.93$, $p<.0001$ ). The post hoc test showed that the adults' use of these two types of gesture was significantly higher than that of both groups of children $(p<.05)$.

Table 3

Mean numbers (S.D.) of main types of gesture for each age group.

\begin{tabular}{lcll} 
& $\begin{array}{l}\text { Representational } \\
\text { gestures }\end{array}$ & $\begin{array}{l}\text { Framing } \\
\text { gestures }\end{array}$ & $\begin{array}{l}\text { Discursive } \\
\text { gestures }\end{array}$ \\
\hline 6-Year-olds & $3.78(6.13)$ & $0.92(1.42)$ & $0.31(0.56)$ \\
10-Year-olds & $12.81(18.58)$ & $3.18(4.24)$ & $2.81(5.14)$ \\
Adults & $14.05(14.54)$ & $5.07(4.52)$ & $7.26(7.17)$ \\
\hline
\end{tabular}




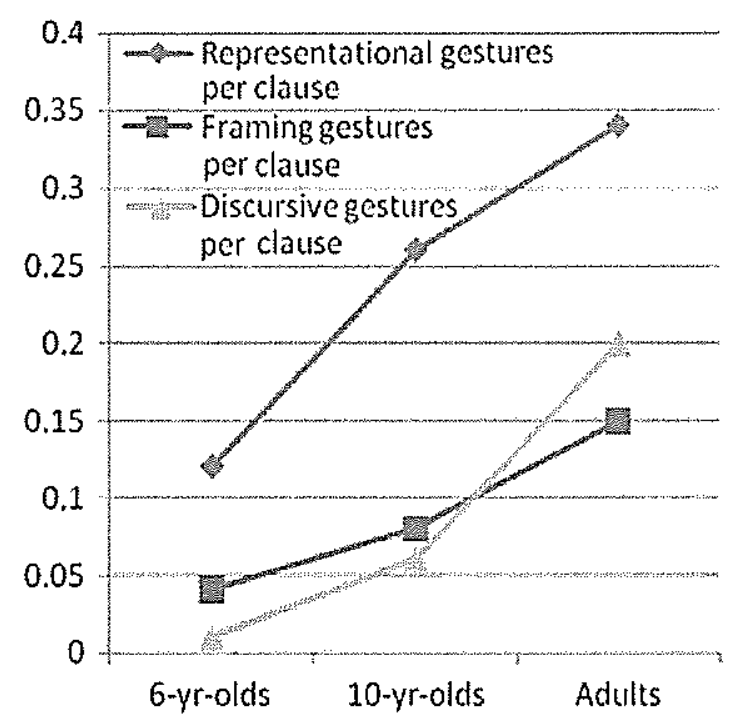

Fig. 5. Main gesture types (rates) for each age group.

Thirdly, we analysed the gesture-speech combinations. Gestures could either reinforce, integrate, supplement, contradict, complement or substitute speech. The analysis revealed sparse use of the following relations: contradiction, complementation and substitution. Like the infrequent use of certain types of gesture, this may also have stemmed from the specific nature of the language task, which required coherence in the telling of the story, no deixis and explicit verbal information, rather than emblematic use of gestures. Consequently, we excluded these three types of gesture-speech combination from our statistical analysis, leaving the three remaining combinations: reinforcement, integration and supplementation. In order to control for the effect of narrative length, we not only considered their number (see Table 4), but also their rate (i.e. the number of strokes per clause, see Fig. 6).

In the ANOVA, age was regarded as a between-subjects factor and nature of the combinations as a within-subjects factor. Both factors had a significant effect. For the age effect $(F(2,119)=24.41, p<.0001)$, post hoc Bonferroni tests showed that it only concerned the difference between the younger children and the other two groups $(p<.05)$. For the nature of combination effect $(F(2,238)=13.57$, $p<.0001$ ), post hoc Bonferroni tests showed that the most frequent gesture-speech combination was integration, which was significantly different from the others $(p<.05)$.

Table 4

Mean numbers (S.D.) of main gesture-speech combinations for each age group.

\begin{tabular}{llcl}
\hline & Reinforces & Integrates & Supplements \\
\hline 6-Year-olds & $1.20(1.35)$ & $3.05(4.37)$ & $1.63(2.50)$ \\
10-Year-olds & $3.74(6.35)$ & $10.33(13.33)$ & $6.60(10.02)$ \\
Adults & $8.13(7.04)$ & $11.68(12.21)$ & $8.55(7.00)$ \\
\hline
\end{tabular}

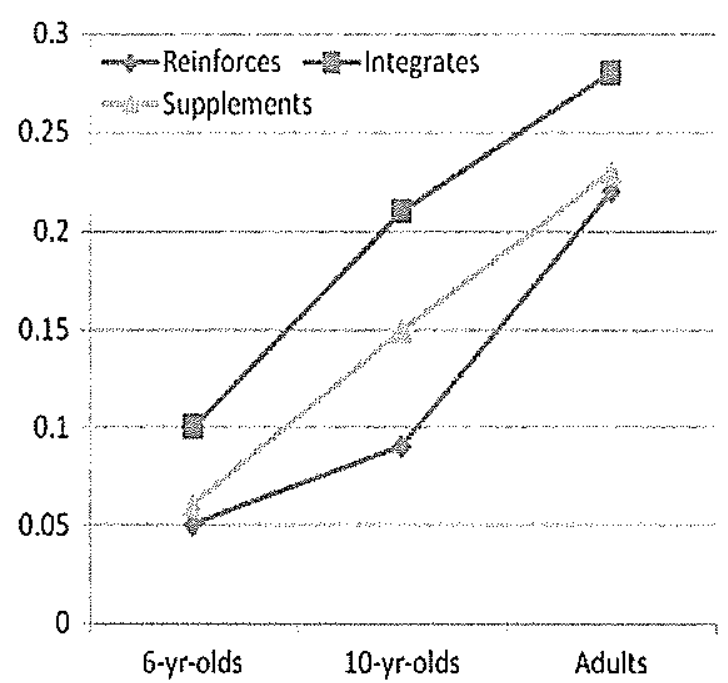

Fig. 6. Main gesture-speech combinations (rates) for each age group.

The interaction between age and type of combination $(F(4,238)=1.32, p=.263)$ failed to reach significance.

The high proportion of integration combinations was directly related to the high proportion of representational gestures, for as indicated in Section 2.3.3.3, most of the representational gestures were coded as integrating gestural information with speech. Their increase with age was thus linked to the increase in representational gestures. We also hypothesized a related change between reinforcement and supplementation, with an increase in supplementation combinations compared with reinforcement combinations. However, the results revealed a significant increase between 6 and 10 years for both types of combination and did not, therefore, settle the issue one way or the other.

\section{Discussion and conclusions}

In this study, we investigated the nature and strength of the developmental changes that occur in the use of language and co-speech gesture in narration. Our objective was first to elicit the same kind of language behaviour under controlled conditions in all three age groups (6year-old children, 10-year-old children and adults), and second to test our hypothesis on a large volume of data. We predicted age-related changes in the length and complexity of the narratives and in the use of co-speech gestures.

Firstly, regarding linguistic changes, the 10-year-old children produced longer narratives than the 6-year-olds, while the adults produced shorter narratives with fewer connective markers and anaphoric expressions than the 10-year-olds. Young children's difficulty to summarize may explain this unexpected result: the 10-year-old children tried to tell the story in its entirety - and were more successful in this than the 6-year-olds -, while the adults tended to give summarized accounts of the story. As for cohesion markers, the less frequent use of connectors and 
anaphoric expressions in the adults' narratives may have been related to their mastery of more implicit communication means (inferential links between clauses, subject ellipsis). A very different picture emerged, however, when we looked at syntax and discourse complexity markers. Although the adults produced shorter narratives than the 10-year-olds, they used significantly more complex sentences and they commented, explained and interpreted the narrated events significantly more than the 10 -year-olds did. This shift towards more complex syntax and more complex discourse structures was also observed in the 10 year-olds, compared with the 6-year-olds.

Secondly, regarding the use of gesture in narrative activity, our results showed a steady increase with age. The adults gestured slightly more than the 10-year-olds who, in turn, gestured more than the 6-year-olds. We hypothesized that the significant increase between the ages of 6 and 10 was linked to the length of the narratives: as they produced longer narratives, the 10-year-olds produced a larger number of gestures. However, the gesture rate also showed a constant increase with age, which was not related to the length of the narratives: although the adults produced shorter narratives, they still gestured significantly more than both groups of children. Our results thus support the claim that the use of co-speech gestures as a semiotic resource develops with age. More specifically, our results showed a greater increase in non-representational gestures than in representational ones: the adults used more framing and discourse cohesion gestures than the 10-year-olds who, in turn, used significantly more of these than the 6-year-olds. The higher proportion of cohesive gestures in the adults' repertoire is consistent with the idea that discourse cohesion develops with age, even though their narratives did not contain significantly more linguistic connectors or anaphors than the children's ones. The higher proportion of framing gestures in their repertoire provides additional evidence for a developmental shift towards more complex discourse behaviour at the pragmatic level. As we previously observed in children's spontaneous multimodal narratives (Colletta, 2009), framing gestures often accompany and fiag up comments on the narratives. The above results are thus consistent with the fact that the adults produced significantly more non-narrative clauses than either group of children.

In summary, our results support the notion that gesture and narrative production co-develop with age. But what do they tell us in relation to the theoretical issue of the gesture-speech relationship?

As stated in Section 1, the literature has generated a number of models intended to formalise the relationship between speech and gesture. Some of them, in particular the Growth Point Theory (McNeill and Duncan, 2000) and the Interface Hypothesis (Kita and Özyürek, 2003), regard gestures as an integral part of the utterance. Others regard speech and gesture production as partly separate processes (Krauss et al., 2000; de Ruiter, 2000). Apart from their theoretical disagreement regarding the cognitive processes underlying speech and gesture production, these models all focus on the same issue, that of iconic representational gestures accompanying speech. As Kita and Özyürek (2007) put it, the way in which iconic gesture interplays with speech in the coding of certain key representations, such as spatial localisation and movement, is a crucial issue when it comes to understanding the part played by both modalities in thinking for speaking.

However, the above-mentioned theoretical models remain limited in their scope. For instance, they do not explore the gesture-speech relationship with regard to the planning of speech in discourse construction and cohesion, nor do they consider it with regard to the coding of communicative intentions. Our results, together with Graziano's observations on Italian data (Graziano, 2009), provide evidence that discourse colesion gestures and framing gestures play a substantial part in narrative production. A closer investigation of the role played by discursive and framing gestures in discourse comprehension would allow us to test these models and extend their relevance. The above-mentioned models also fail to investigate the gesture-speech relationship with regard to language development. In early development, the role played by pointing - and by other gestures that form part of a child's initial gestural repertoire - in the acquisition of linguistic abilities has already been established in Italian and American studies. In later development, the nature of the interplay between linguistic and gesture resources in discourse production and the way in which it changes with age remain largely unknown, as does the role played by cognitive and social factors in the child's multimodal language behaviour.

The current study sheds new light on some previously neglected aspects of multimodal discourse development. Firstly, it provides evidence for a developmental shift towards complex or heterogeneous narrative production and the marking of discourse cohesion. In our view, the age-related tendency to enrich oral narratives with various types of comments can be analysed both from the point of view of cognitive development, insofar as it reveals cognitive decentring, and from the point of view of social development, insofar as it reveals new social conversational abilities.

Secondly, the present study provides evidence for a close and intricate relationship between gesture and speech in discourse behaviour and development. For instance, cospeech gesture and linguistic variables appear to co-vary at all ages. More specifically, adults use gestures to mark cohesion, in addition to linguistic cohesion cues. As for gesture-speech combinations, the reinforcement of speech by gestures seems to persist with age in a real, albeit rather unexpected way, alongside integration and supplementation. The question raised by this very close relationship is that of the exact role of gesture in the process of discourse development: do adults - and, in some respects, 10-yearolds - gesture to mark additional discourse information, complexity and cohesion, or does gesture production 
promote the process of discourse production? Evidently, finding answers to this question will require further analysis.

\section{Acknowledgements}

This research was supported by grant no. 0178-01 from the ANR (French National Research Agency) project entitled "L'acquisition et les troubles du langage au regard de la multimodalité de la communication parlée". We are grateful to Isabelle Rousset from Lidilem, and to all the children and adult students who took part in this study.

Appendix:. Copy of the ELAN annotation window file
Capirci, O., Volterra, V., 2008. Gesture and speech: the emergence and development of a strong and changing partnership. Gesture 8 (1), 2244.

Capirci, O., Iverson, J.M., Pizzuto, E., Volterra, V., 1996. Gesture and words during the transition to two-word speech. Journal of Child Language 23 (3), 645-673.

Capirci, O., Caselli, M.C., Iverson, J.M., Pizzuto, E., Volterra, V., 2002. Gesture and the nature of language in infancy: the role of gesture as a transitional device en route to two-word speech. In: Armstrong, D.A., Karchmer, M.A., Cleeve, J.V. (Eds.), Essays in Honor of William C. Stokoe: The Study of Signed Languages. Gallaudet University Press, Washington, DC, pp. 213-246.

Capirci, O., Cristilli, C., Graziano, M., Guidarelli, B., Langella, E., Pellecchia, G., Varuzzi, C., 2007. Developmental aspects of the relationship between speech and gesture in the construction of narratives. In: Proceedings of the Third International Society for Gesture Studies Conference, Evanston, IL, June.

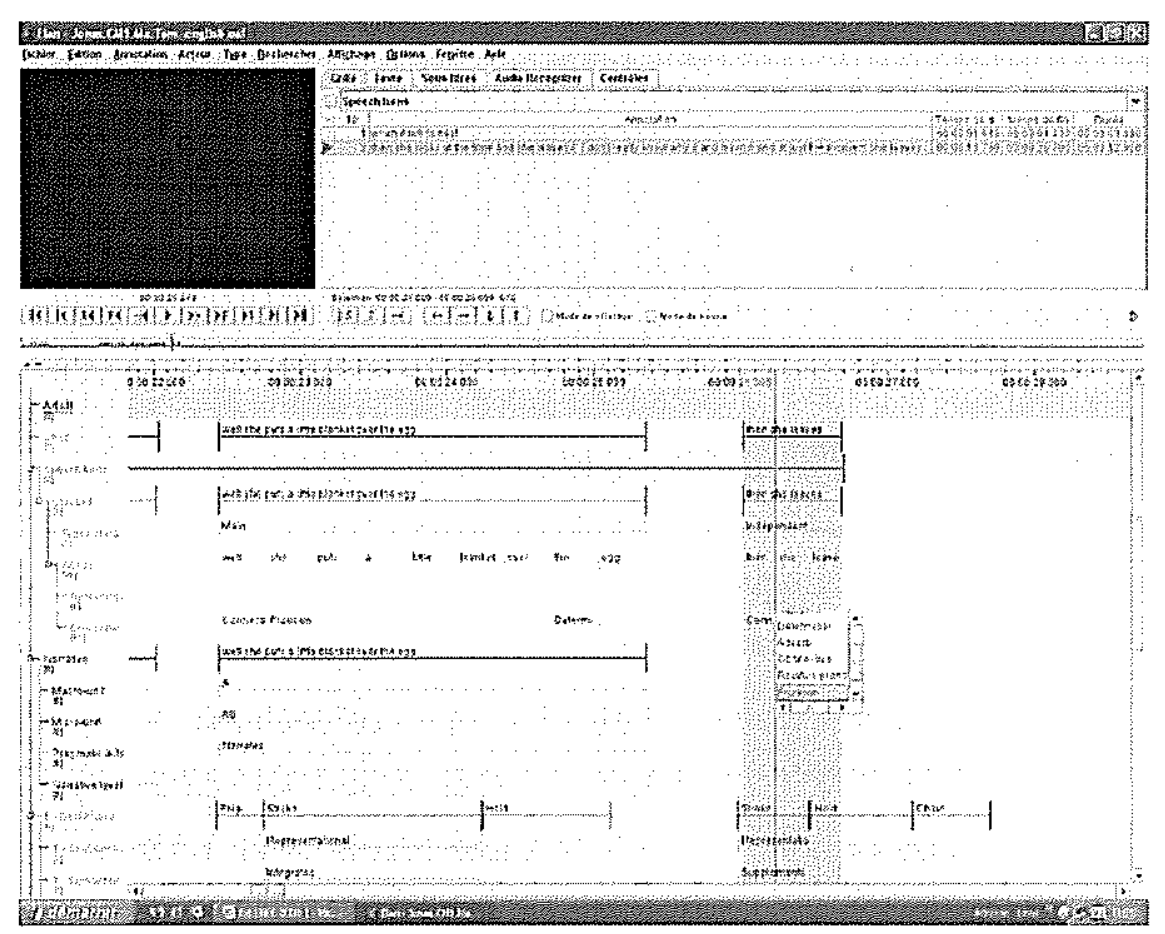

\section{References}

Bamberg, M., 1987. The Acquisition of Narratives: Learning to Use Language. Mouton de Gruyter, Berlin.

Beattie, C., Shovelton, H., 1999. Do iconic hand gestures really contribute anything to the semantic information conveyed in speech? An experimental investigation. Semiotica 123, 1-30.

Berman, R.A., Slobin, D.I., 1994. Relating Events in Narrative: A Crosstinguistic Developmental Study. Lawrence Erlbaum Associates, Hillsdale.

Bouvet, D., 2001. La Dimension Corporelle de la Parole. Peeters, Paris. Butcher, C., Goldin-Meadow, S., 2000. Gesture and the transition from one- to two-word speech: when hand and mouth come together. In: McNeill, D. (Ed.), Language and Gesture. Cambridge University Press, Cambridge, pp. 235-257.

Caibris, G., 2003. L'Expression Gestuelle de la Pensée d'un Homme Politique. CNRS Éditions, Paris.
Coirier, P., Gaonac'h, D., Passerault, J.-M., 1996. Psycholinguistique textuelle. Approche cognitive de la compréhension et de la production des textes. Armand Colin, Paris.

Colletta, J.-M., 2004. Le Développement de la Parole Chez l'Enfant Agé de 6 à 11 ans. Corps, Langage et Cognition. Mardaga, Hayen.

Colletta, J.-M., 2009. Comparative analysis of children's narratives at different ages: a multimodal approach. Gesture 9 (1), 61-97.

Colletta, J.-M., Pellenq, C., 2009. Multimodal explanations in French children aged from 3 to 11 years. In: Nippold, N., Scott, C. (Eds.), Expository Discourse Development and Disorders: International Perspectives, Erlbaum. Taylor \& Francis, New York, pp. 63-97.

Colletta, J.M., Kunene, R., Venouil, A., Kaufmann, V., Simon, J.P., 2009. Multitrack annotation of child language and gestures. In: Kipp, $M$. (Ed.), Multimodal Corpora. Springer.

de Ruiter, J.P., 2000. The production of gesture and speech. In: McNeill, D. (Ed.), Language and Gesture. Cambridge University Press, Cambriclge, pp. 284-311. 
Diessel, H., 2004. The acquisition of complex sentences. Cambridge Studies in Linguistics, vol. 105. Cambridge University Press, Cambridge.

Ducey-Kaufmann, V., 2007. Le Cadre de la Parole et le Cadre du Signe: un Rendez-vous Développemental. Thèse de Doctorat en Sciences du Langage, Université Stendhal, Grenoble.

Fayol, M., 1985, Le Récit et sa Construction, une Approche de Psychologie Cognitive. Delachaux et Niestié, Neuchâtel.

Fayol, M., 1997. Des idées au texte Psychologie cognitive de la production verbale, orale et écrite. P.U.F., Paris.

Feyereisen, P., 1994. Le Cerveau et la Communication. P.U.F., Paris.

Goldin-Meadow, S., Butcher, C., 2003. Pointing toward two-word speech in young children. In: Kita, S. (Ed.), Pointing: Where Language, Culture, and Cognition Meet. Lawrence Erlbaum Associates, Mahwah, pp. 85-107.

Gombert, J.-E., 1990. Le Développement Métalinguistique. P.U.F., Paris.

Graziano, M., 2009. Le développement de la relation entre les compétences verbale et gestuelle dans la construction d'un texte narratif chez l'enfant âgé de 4 à 10 ans. Ph.D. Dissertation, Université Stendhal, Grenoble \& Università degli Studi Suor Orsola Benincasa, Napoli.

Guidetti, M., 2002. The emergence of pragmatics: forms and functions of conventional gestures in young French children. First Language 22 (3), 265-285.

Guidetti, M., 2003. Pragmatique et Psychologie du Développement. Comment Communiquent les Jeunes Enfants. Belin, Paris.

Gullberg, M., de Bot, K., Volterra, V., 2008a. Gestures and some key issues in the study of language development. Gesture 8 (2), 149179.

Gullberg, M., Hendricks, H., Hickmann, M., 2008b. Learning to talk and gesture about motion in French. First Langunge 28 (2), 200-236.

Hadar, U., Butterworth, B., 1997. Iconic gestures, imagery and word retrieval in speech. Semiotica 115, 147-172.

Halliday, M.A.K., Hasan, R., 1976. Cohesion in English. Longman, London.

Hickmann, M., 2003. Children's Discourse: Person, Space and Time Across Languages. Cambridge University Press, Cambridge.

Iverson, J.M., Goldin-Meadow, S. (Eds.), 1998. The Nature and Functions of Gesture in Children's Communication. New Directions for Child Development, vol. 79. Jossey-Bass, San Francisco.

Jisa, H., 2000. Increasing cohesion in narratives: a developmental study of maintaining and reintroducing subjects in French. Linguistics 38 (3) 591-620.

Jisa, H., 2004. Growing into academic French. In: Berman, R. (Ed.), Language Development Across Childhood and Adolescence: Trends in Language Acquisition Research. John Benjamins, Amsterdam, Philadelphia, pp. 135-161.

Kendon, A., 1980. Gesticulation and speech: two aspects of the process of utterance. In: Kay, M.R. (Ed.), The Relation between Verbal and Nonverbal Communication. La Hague, Mouton, pp. 207-227.

Kendon, A., 2004. Gesture: Visible Action as Utterance. Cambridge University Press, Cambridge.

Kita, S., 2000. How representational gestures help speaking. In: McNeill, D. (Ed.), Language and Gesture. Cambridge University Press, Cambridge, pp. 162-185.

Kita, S., Özyürek, A., 2003. What does cross-linguistic variation in semantic coordination of speech and gesture reveal? Evidence for an interface representation of spatial thinking and speaking. Journal of Memory and Language 48, 16-32.

Kita, S., Özyürek, A., 2007. How does spoken language shape iconic gestures. In: Duncnn, S., Cassell, J., Levy, E.T. (Eds.), Gesture and the
Dynamic Dimension of Language: Essays in Honor of David McNeill. John Benjamins, Amsterdam, pp. 67-74.

Kita, S., Özyürek, A., Allen, A.S., Brown, A., Furman, R., Ishizuka, T., 2007. Relations between syntactic encoding and co-speech gestures: implications for a model of specch and gesture production. Language and Cognitive Processes $22(8), 1212-1236$.

Krauss, R.M., Chen, Y,, Gottesman, R.F,, 2000. Lexical gestures and lexical access: a process model. In: McNeill, D. (Ed.), Language and Gesture. Cambridge University Press, Cambridge, pp. 261-283.

Kunene, R., Colletta, J.-M., 2007. Exploration of multimodal narratives: a cross-language comparison of isizulu and French. In: Proceedings of the 10th International Pragmatics Conference, Göteborg, July 8-13.

Labov, W., 1978. Le Parler Ordinaire. Minuit, Paris.

Laforest, M., 1996. Autour de la Narration. Nutit Blanche Editeur, Laval, Quebec.

Léonard, J.-L., Pinheiro, M.-B., 1993. Enonciation et non verbal: aspects de la cohésion linguistique dans un récit oral poitevin. Langage et Société 65, 39-68.

Lundquist, L., 1980. La Cohérence Textuelle: Syntaxe Sémantique, Pragmatique. Nyt Nordisk Forlag Arnold Busk, Copenhagen.

Marcos, H., 1998. De la Communication Prélinguistique à la Communication Linguistique: Formes et Fonctions. L'Harmattan, Paris.

Mayberry, R., Jaques, J., 2000. Gesture production during stuttered speech: insights into the nature of gesture-speech integration. In McNeill, D. (Ed.), Language and Gesture. Cambridge University Press, Cambridge, pp. 199-214.

McNeill, D., 1992. Hand and Mind. What Gestures Revenl About Thought. University of Chicago Press, Chicago.

McNeill, D., Duncan, S.D., 2000. Growth points in thinking for speaking. In: McNeill, D. (Ed.), Language and Gesture. Cambridge University Press, Cambridge, pp. 141-161.

Nicoladis, E., Marentette, P., Navarro, S., 2008. The role of gestures in children narratives: evidence from English, French and Spanish. In: Proceedings of the XI International Congress for the Study of Child Language (IASCL), Edinburgh, 28 July-1 August.

Özçaliskan, S., Goldin-Meadow, S., 2006. How gesture helps children construct language. In: Clark, E.V., Kelly, B.F. (Eds.), Constructions in Acquisition. CSLI Publications, Palo Aito, pp. 31-58.

Ozyurek, A., Kita, S., Allen, S., Brown, A., Furman, R., Ishizuka, T., 2008. Development of cross-linguistic variation in speech and gesture: motion events in English and Turkish. Developmental Psychology 44 (4), 1040-1054

Pizzulo, E., Capobianco, M., 2007. The link and differences between deixis and symbols in children's early gestural-vocal system. In: Liebal, K., Muller, C., Pika, S. (Eds.), Gestural Communication in Nonhuman and Human Primates. John Benjamins, Amsterdam, pp. 164-181.

Rimé, B., Schiratura, L., 1991. Gesture and speech. In: Feldman, R. Rimé, B. (Eds.), Fundamentals of Nonverbal Behavior. Cambridge University Press, Cambridge, pp. 239-281.

Sperber, D., Wilson, D., 1989. La pertinence. Communication et Cognition. Minuit, Paris.

Streeck, J., Knapp, M.L., 1992. The interaction of visual and verbal features in human communication. In: Poyatos, F. (Ed.), Advances in Nonverbal Communication. John Benjamins, Amsterdam, pp. 3-23.

Thompson, L.A., Massaro, D.W., 1994. Children's integration of speech and pointing gestures in comprehension. Journal of Experimental Child Psychology 57, 327-354.

Tolchinsky, L., 2004. The nature and scope of later language development. In: Berman, R.A. (Ed.), Language Development Across Childhood and Adolescence. John Benjamins, Amsterdam, pp. 233-247.

Van Der Stratten, A., 1991. Premiers, Gestes Premiers Mots. Centurion, Paris. 